\title{
I mplementasi Reflector Antena Wajanbolik Pada Layanan EVDO (Evolution Data Optimized)
}

\author{
BI MA ${ }^{1}$, LITA LI DYAWATI ${ }^{2}$, ARSYAD RAMADHAN.D ${ }^{3}$ \\ 1. Teknik Elektro Institut Teknologi Nasional \\ 2. Teknik Elektro Institut Teknologi Nasional \\ 3. Teknik Elektro Institut Teknologi Nasional \\ Email :B1ma_bdg@yahoo.com
}

\begin{abstract}
ABSTRAK
Antena merupakan perangkat yang memiliki peranan yang sangat penting dalam sistem komunikasi tanpa kabel (wireless). Pada penelitian ini akan diimplementasikan reflektor antena wajanbolik yang beroperasi pada frekuensi CDMA 2000 1x EVDO 1900 MHz. Antena ini menggunakan reflektor dari wajan, dengan waveguide dari pipa paralon yang dilapisi dengan lakban alumunium, dan penerima sinyal menggunakan USB modem adapter. Antena ini ditujukan untuk menjadi media bantu dalam memperkuat penerimaan sinyal EVDO dan memaksimalkan dan kecepatan transfer data. Antena ini memberikan gain sebesar 15,530 $d B$ berdasarkan pengukuran dan 15,156 dB berdasarkan teoritis. Pengujian menggunakan wajanbolik menunjukkan adanya peningkatan level sinyal modem yang terendah sebesar $4 d B$ pada pengukuran dengan kondisi indoor di siang hari serta tertinggi sebesar 19 dB pada pengukuran dengan kondisi outdoor di malam hari. Hasil dari pengujian pun menunjukkan peningkatan kecepatan transfer data rata - rata sebesar 42 KBps sampai dengan 269 KBps dibandingkan pengukuran tanpa wajanbolik.
\end{abstract}

Kata kunci: Reflektor, Waveguide, Wajanbolik, USB adapter, EVDO.

\begin{abstract}
The antenna is a device that has a very important role in wireless communication systems (wireless). In this research will be implemented wajanbolik reflector antenna which operates at frequencies of CDMA 2000 1x EVDO $1900 \mathrm{MHz}$. This antenna uses a reflector of the pan, with the waveguide of the pipe is coated with aluminum duct tape, and a signal receiver using a USB modem adapter. This antenna is intended to be a media aids in strengthening the EVDO and signal reception to maximize data transfer speeds. This antenna give a gain of 16.015 from measurement $\mathrm{dBi}$ and $15.156 \mathrm{dBi}$ based on theory. Tests using wajanbolik showed an increase in the level of modem signals a low of $4 d B$ in measurement with indoor conditions during the day and $19 \mathrm{~dB}$ at the peak of measurements with outdoor conditions at night. Results of testing also showed an increase in average data transfer rate is 42 KBps up to 269 KBps compared to measurements without wajanbolik.
\end{abstract}

Keywords: Reflector, Waveguide, Wajanbolic, USB adapter, EVDO. 


\section{PENDAHULUAN}

Internet telah menjadi kebutuhan penting. Bahkan bagi sebagian orang, internet telah menjadi kebutuhan primer. Perkembangan teknologi mobile telah memberi kemudahankemudahan untuk dapat mengakses media informasi global ini. Jaringan mobile sebagian besar telah memenuhi standar koneksi dengan teknologi 3G (3 Generation), Next G atau HSDPA(High-Speed Downlink Packet Access) yang semakin mempermudah pengguna untuk mendapatkan layanan internet. Kendala yang umum terjadi adalah kecepatan akses yang sering menjadi lambat. Untuk mengatasi penurunan kecepatan akses ini digunakan standar EV-DO (Evolution Data Optimized) yang merupakan sebuah standar pada wireless broadband berkecepatan tinggi dengan mengadopsi IP (Internet Protocol).

Menurut penjelasan Stallings (Stallings, 2007) Sistem nirkabel $3 G$ pertama yang diturunkan secara komersial dikenal sebagai CDMA2000 1x EV-DO, juga disebut CDMA/HDR (CDMA High Data Rate). Maksud sistem ini adalah untuk menawarkan laju data paket broadband untuk akses nirkabel ke internet. EV menunjukkan bahwa system ini adalah teknologi evolusioner yang dibangun diatas standar IS-95 (/nterim Standart 95). Yang membedakan skema ini dari teknologi $3 G$ lainnya adalah skema ini dirancang untuk layanan khusus data dan ditujukan untuk penggunaan IP (/nternet Protocol) untuk transmisi paket dan untuk akses internet.

Namun pengembangan EV-DO masih terbatas untuk wilayah-wilayah tertentu bahkan pada beberapa kota, provider EV-DO hanya memilih basis pemasangan perangkat pada wilayah kampus. Hal ini mengakibatkan jangkauan untuk dapat menerima sinyal EV-DO menjadi sempit. Bagi mereka yang hanya dapat melakukan koneksi dari lokasi yang jauh dari pemancar sinyal EV-DO akan sangat kesulitan untuk mengaksesnya. Upaya yang dapat dilakukan adalah memperkuat penerimaan sinyal dengan memasang antena yang memiliki penguatan tinggi. Berdasarkan perancangan antena yang dilakukan Onno W Purbo (Purbo, 2007) antena wajanbolik adalah pilihan yang tepat dengan penguatan yang cukup besar. Antena wajanbolik sangat mungkin dibuat oleh masyarakat umum dengan memperhatikan urutan pengerjaan yang tepat.

Pada tahun 2011 telah dilakukan penelitian tentang "Perancangan dan Realisasi Penguat Pada Wifi" oleh Widita P Rahman (Rahman, 2011) yang hanya terbatas pada pembuatan perangkat lunak simulasi wajanbolik, dan pada tahun 2012 Nugraha (Yurandi, 2012) telah melakukan penelitian tentang "Perancangan dan Implementasi Reflector Antena Wifi dengan Frekuensi 2,4 GHz" yang lebih menekankan pada perbandingan antara reflektor wajan dan reflektor grid dalam hal perolehan sejumlah access point. Oleh karena itu, pada penelitian ini akan diambil judul "Implementasi Reflector Antena Wajanbolik pada layanan EV-DO (Evolution-Data Optimized)" yang akan dihasilkan sebuah antena yang dapat memperkuat penerimaan sinyal EV-DO pada frekuensi $1900 \mathrm{MHz}$ dan memberikan kecepatan transfer yang optimal.

\section{METODOLOGI PENELITIAN}

\subsection{Model Rancangan Reflector Antena Wajanbolik}

Gambar 1 menunjukkan adalah model perancangan dari reflector antena wajanbolik yang terdiri dari dua bagian utama, yaitu wajan dan pipa PVC sebagai pencatu (feeder). 


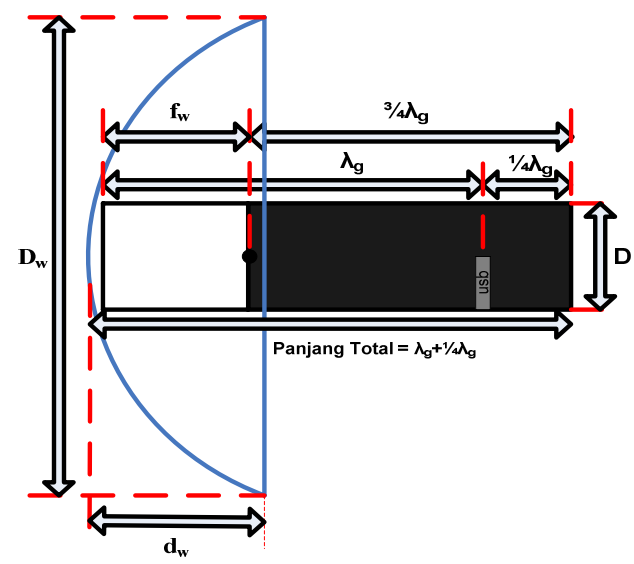

\section{Gambar 1. Pemodelan Reflector Antena Wajanbolik.}

Parameter yang dibutuhkan pada perancangan reflector antena wajanbolik diatas yaitu:

1. Panjang gelombang di udara $(\lambda)$

$$
\lambda=\frac{c}{f}
$$

Dimana:

$c=$ Kecepatan cahaya di udara $\left(3 \times 10^{8} \mathrm{~m} / \mathrm{s}\right)$

$f=$ Frekuensi yang digunakan $(1900 \mathrm{MHz})$

2. Fokus wajan $\left(f_{w}\right)$

$$
f_{w}=\frac{D_{w}{ }^{2}}{16 x d_{w}}
$$

Dimana:

$$
D_{W}=\text { Diameter reflektor }(45,5 \mathrm{~cm})
$$

$\mathrm{d}_{\mathrm{w}}=$ Kedalaman reflektor $(14 \mathrm{~cm})$

3. Diameter pipa PVC (D)

$$
0,60 \lambda<D<0,75 \lambda
$$

4. Panjang gelombang di dalam pipa PVC $\left(\lambda_{G}\right)$

$$
\lambda_{\mathrm{G}}=\left[\frac{\lambda}{\sqrt{1-\left(\frac{\lambda}{1,706 \times \mathrm{D}}\right)^{2}}}\right]
$$

Dimana:

$$
\begin{aligned}
& \lambda=\text { Panjang gelombang di udara } \\
& D=\text { Diameter pipa PVCyang digunakan }
\end{aligned}
$$

5. Panjang pipa PVC yang di lapisi alumunium $\left(\frac{3}{4} x \lambda_{G}\right)$

6. Letak posisi USB modem $\left(\frac{1}{4} x \lambda_{\mathrm{G}}\right)$

7. Panjang total pipa PVC

$$
P_{\text {total }}=\lambda_{\mathrm{G}}+\frac{1}{4} \times \lambda_{\mathrm{G}}
$$

Perhitungan gain dilakukan dengan membandingkan hasil dari pengukuran dan secara teoritis :

- Secara pengukuran

$$
\begin{aligned}
& \mathrm{G}=e \times \mathrm{D} \\
& \mathrm{D}=\frac{41000}{\theta_{H} x \theta_{E}}
\end{aligned}
$$

dimana:

$$
\begin{aligned}
& e=\text { Efisiensi wajan }(0,4) \\
& \mathrm{D}=\text { Directivity }
\end{aligned}
$$


$\theta_{H}=$ Sudut pada titik setengah daya bidang $\mathrm{H}\left({ }^{\circ}\right)$

$\theta_{E}=$ Sudut pada titik setengah daya bidang $\mathrm{E}\left({ }^{\circ}\right)$

- Secara teoritis (Trisapto, 2004)

$\mathrm{G}=10 \log e+20 \log \mathrm{f}+20 \log \mathrm{D}_{\mathrm{w}}+20,4$

dimana:

$e=$ Efisiensi wajan $(0,4)$

$f=$ Frekuensi yang digunakan

$D_{\mathrm{w}}=$ Diameter reflektor

Nilai-nilai variabel perancangan antena wajanbolik diatas dapat di masukkan ke dalam Tabel 1, sebagai berikut:

Tabel 1. Variabel perancangan reflectorantena wajanbolik

\begin{tabular}{|c|l|l|l|}
\hline No & \multicolumn{1}{|c|}{ Variabel } & \multicolumn{1}{c|}{ I nputan } & \multicolumn{1}{c|}{ Hasil } \\
\hline 1 & Titik Fokus & $\begin{array}{l}\mathrm{D}_{\mathrm{W}}=45,5 \mathrm{~cm} \\
\mathrm{~d}_{\mathrm{W}}=14 \mathrm{~cm}\end{array}$ & $\mathrm{f}_{\mathrm{W}}=9,242 \mathrm{~cm}$ \\
\hline 2 & Feeder & Frekuensi $=1,9 \mathrm{GHz}$ & $\lambda_{\mathrm{G}}=29,221 \mathrm{~cm}$ \\
& & Diameter $=11 \mathrm{~cm}$ & $\frac{3}{4} \times \lambda_{\mathrm{G}}=21,915 \mathrm{~cm}$ \\
& & $\frac{1}{4} \times \lambda_{\mathrm{G}}=7,305 \mathrm{~cm}$ \\
\hline 3 & & & $\lambda_{\mathrm{G}}+\frac{1}{4} \times \lambda_{\mathrm{G}}=36,525 \mathrm{~cm}$ \\
& & & \\
\hline
\end{tabular}

\subsection{I mplementasi Reflektor Antena Wajanbolik}

Tahap-tahap pembuatan reflektor antena wajanbolik dapat dijelaskan sebagai berikut :

1. Persiapkan semua alat dan bahan yang dibutuhkan seperti wajan, baut, pipa PVC beserta tutup pipa dan alumunium foil.

2. Melakukan perhitungan parameter-parameter antena wajanbolik.

3. Bor wajan dan tutup pipa PVC di tengah lalu baut tutup pipa PVC dan wajan di tengah wajan seperti pada Gambar 2.

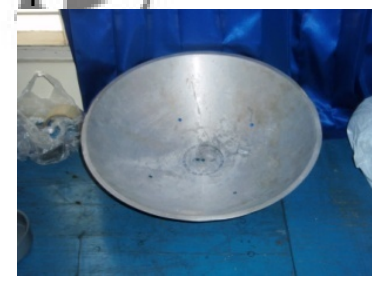

(a)

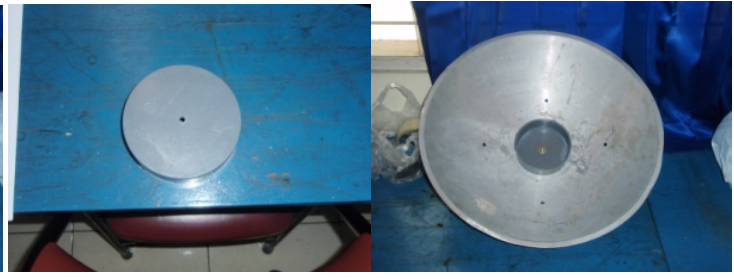

(b) (c)

Gambar 2. Pemasangan tutup paralon pada wajan (a) wajan alumunium (b) Tutup pipaPVC (c) wajan yang telah terpasang tutup pipa PVC

4. Lubangi pipa paralon sebagai tempat dudukan USB modem EVDO lalu lapisi pipa paralon dengan lakban alumunium di bagian luar seperti Gambar 3(a). Siapkan tutup pipa PVC yang lain, kemudian lapisi tutup pipa tersebut dengan lakban alumunium di bagian dalamnya seperti Gambar 3(b), lalu pasang pada pipa yang telah dilapisi oleh alumunium sebelumnya seperti pada Gambar 3(c). 


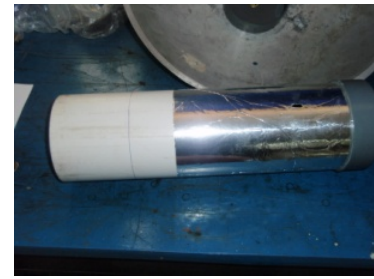

(a)

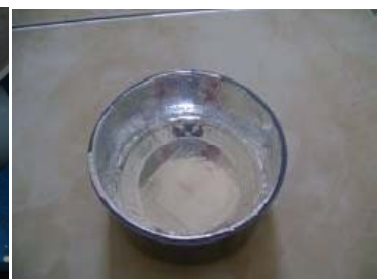

(b)

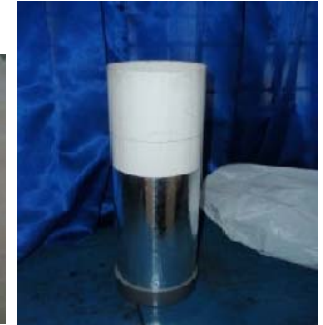

(c)

Gambar 3. Pemasangan tutup paralon pada pipa (a) Pipa yang telah di lubangi (b) Tutup pipa yang telah di bungkus alumunium (c) Pipa PVC yang telah dipasang tutup pipa

5. Masukkan USB modem EVDO ke dalam pipa sebagai dudukan seperti Gambar 4.

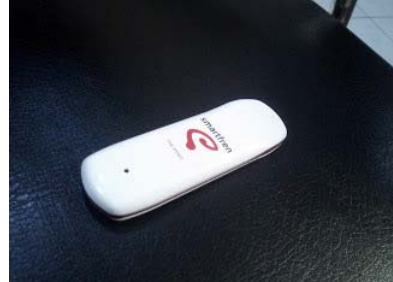

(a)

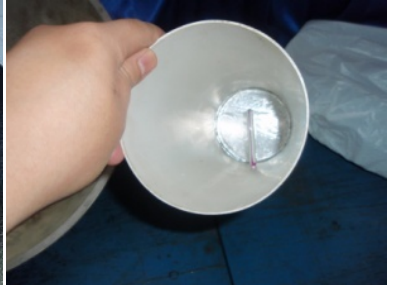

(b)

Gambar 4. Pemasangan USB modem EVDO pada pipa (a) USB modem (b) Modem yang telah dipasang pada pipa PVC

6. Kemudian sambungkan pipa paralon yang telah ditutupi lakban alumunium pada reflektor wajan seperti Gambar 5.

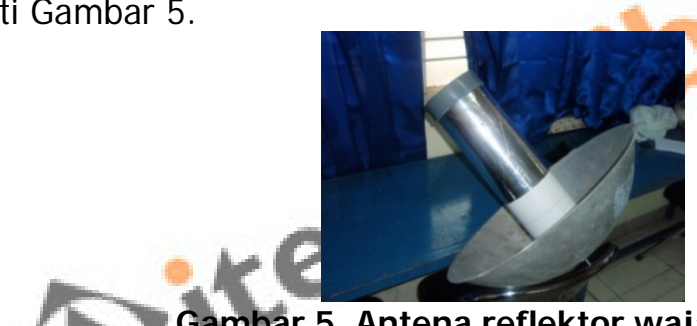

Gambar 5. Antena reflektor wajanbolik.

\section{HASI L DAN PEMBAHASAN}

\subsection{Metode Pengujian}

Setelah selesai proses pembuatan reflektor antena, maka langkah selanjutnya adalah melakukan pengukuran dan pengujian antena yang telah dibuat. Pengukuran dilakukan agar bisa mendapatkan data dari sistem tersebut sehingga dengan data ini dapat mengetahui kinerja dari antena yang telah di rancang. Hasil pengukuran dapat dijadikan sebagai suatu acuan dalam analisa perangkat. Berikut beberapa tahap pengujian dalam penelitian ini :

1. Pengukuran pola radiasi.

2. Pengukuran beamwidth.

3. Pengukuran gain.

4. Pengukuran transfer rate data pada siang dan malam hari juga pada tempat indoor dan outdoor.

\subsection{Pengukuran Pola Radiasi Antena.}

Pengukuran pola radiasi antena dengan reflektor wajanbolik dilakukan secara manual dengan memutar antena tiap $10^{\circ}$ searah jarum jam dengan keterarahan terhadap BTS (Base Transceiver Station) yang dituju. Tabel 2 merupakan data hasil pengukuran pola radiasi vertikal dan horizontal antena wajanbolik. 
Tabel 2. Data pengukuran pola radiasi vertikal dan horizontal antena dengan reflektor wajanbolik

\begin{tabular}{|c|c|c|c|c|c|c|c|c|}
\hline \multirow{2}{*}{$\begin{array}{c}\text { Sudut } \\
\left({ }^{\circ}\right)\end{array}$} & \multicolumn{2}{|c|}{ Level Daya $(\mathrm{dBm})$} & \multirow{2}{*}{$\begin{array}{c}\text { Sudut } \\
\left({ }^{\circ}\right)\end{array}$} & \multicolumn{2}{|c|}{ Level Daya $(\mathrm{dBm})$} & \multirow{2}{*}{$\begin{array}{c}\text { Sudut } \\
\left({ }^{\circ}\right)\end{array}$} & \multicolumn{2}{|c|}{ Level Daya (dBm) } \\
\hline & Vertikal & Horizontal & & Vertikal & Horizontal & & Vertikal & Horizontal \\
\hline 0 & -50 & -51 & 120 & -69 & -71 & 240 & -68 & -71.25 \\
\hline 10 & $-51,5$ & -52.75 & 130 & $-68,75$ & -69.75 & 250 & $-68,5$ & -69.75 \\
\hline 20 & $-53,25$ & -55.5 & 140 & -72 & -72 & 260 & -68 & -70.25 \\
\hline 30 & $-68,25$ & -66.75 & 150 & $-74,75$ & -75.25 & 270 & -64 & -63.5 \\
\hline 40 & -63 & -63.5 & 160 & $-74,75$ & -73.5 & 280 & $-68,25$ & -65.25 \\
\hline 50 & $-65,5$ & -68.5 & 170 & $-78,25$ & -78.75 & 290 & $-63,25$ & -63.25 \\
\hline 60 & $-70,25$ & -71.75 & 180 & $-77,25$ & -77.5 & 300 & -62 & -62.5 \\
\hline 70 & -70 & -69.25 & 190 & -74 & -76 & 310 & $-60,75$ & -66.75 \\
\hline 80 & -60 & -67 & 200 & -75 & -76.25 & 320 & -61 & -61 \\
\hline 90 & -72 & -74 & 210 & -72 & -71.5 & 330 & -66 & -62.5 \\
\hline 100 & $-67,75$ & -65.25 & 220 & $-75,25$ & -73.25 & 340 & $-56,5$ & -54.5 \\
\hline 110 & $-70,25$ & -68.5 & 230 & -70 & -70.75 & 350 & -52 & -52.25 \\
\hline
\end{tabular}

Gambar 6 merupakan gambar pola radiasi antena dengan reflektor wajanbolik yang diplot pada koordinat grafik.

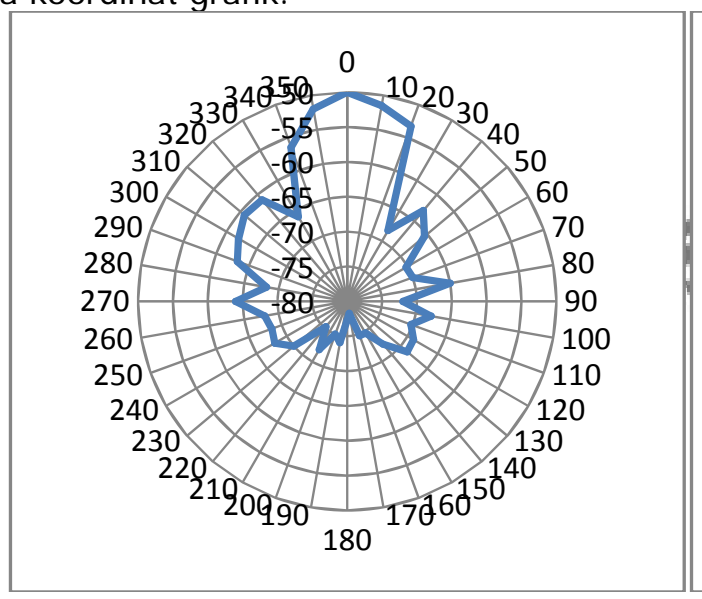

Gambar 6. Pola radiasi Vertikal.

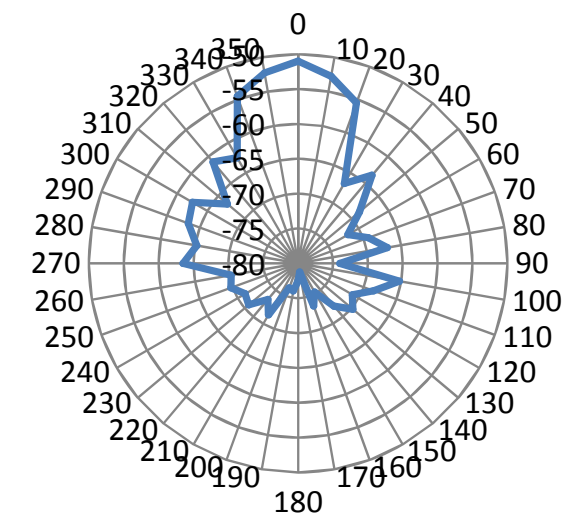

Gambar 7. Pola radiasi Horizontal.

Pada Gambar 6 dan 7 terdapat pola radiasi antena dengan reflektor wajanbolik yang terlihat mengarah pada satu arah tertentu (directionah). Ini disebabkan karena level sinyal terbesar ada pada saat posisi antena $0^{\circ}$, dimana pada posisi tersebut antena menerima sinyal secara maksimal. Karena pada posisi $0^{\circ}$ antena tepat diarahan menghadap BTS yang dituju (BTS SMARTFREN). Dan penerimaan level sinyal terendah terdapat pada posisi $180^{\circ}$ dimana pada posisi tersebut antena tidak tepat mengarah pada pemancar yang dalam hal ini adalah BTS.

\subsection{Pengukuran Beamwidth Antena.}

Gambar 8 dan 9 menunjukkan beamwidth vertikal dan horizontal dari pengukuran antena dengan reflektor wajanbolik. 


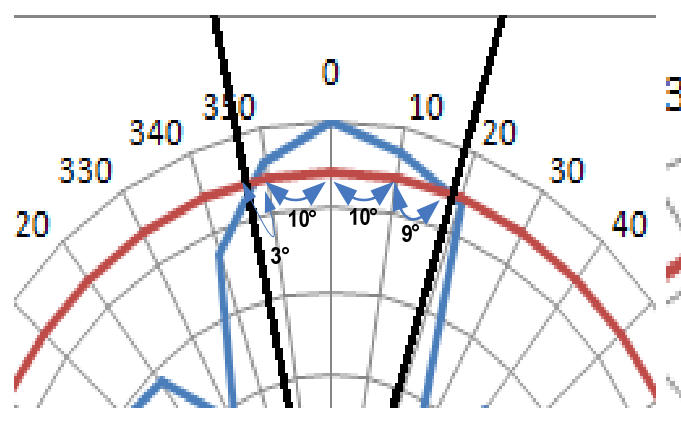

Gambar 8. Beamwidth Vertikal

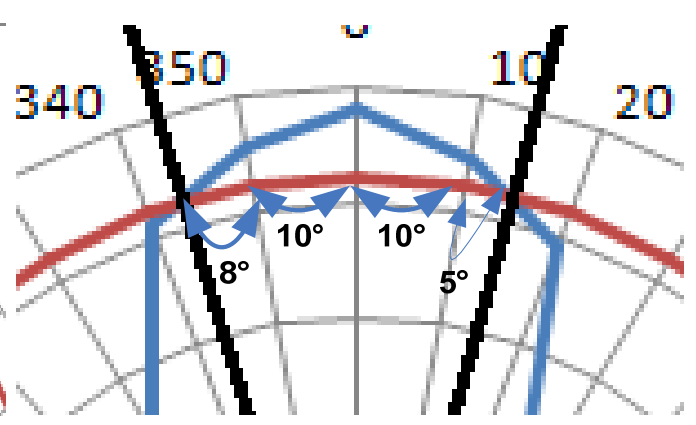

Gambar 9. Beamwidth Horizontal

Pada Gambar 8 terlihat lebar beamwidth yang diperoleh dari daya terima maksimum sebesar $-50 \mathrm{dBm}$ dikurangi setengah daya dalam satuan deciBel sebesar $3 \mathrm{~dB}$ menjadi $-53 \mathrm{dBm}$, sehingga lebar beamwidth vertikal antena dengan reflektor wajanbolik adalah $32^{\circ}$. Sedangkan pada Gambar 9 terlihat lebar beamwidth yang diperoleh dari daya terima maksimum sebesar $-51 \mathrm{dBm}$ dikurangi setengah daya dalam satuan deciBel sebesar $3 \mathrm{~dB}$ menjadi $-54 \mathrm{dBm}$, sehingga lebar beamwidth horizontal antena dengan reflektor wajanbolik adalah $33^{\circ}$.

\subsection{Perhitungan Gain}

Perhitungan gain dilakukan dalam dua tahap yaitu melalui pengukuran dan berdasarkan teori. Dengan menggunakan persamaan (8) dan (9) didapat gain bedasarkan pengukuran sebesar 15,530 dB dan dengan menggunakan persamaan (10) didapat gain berdasarkan teoritis sebesar 15,156 dB. Dengan selisih sebesar 0,374 dB. Terdapat beberapa faktor yang mempengaruhi perhitungan gain, seperti ketepatan dalam pembacaan level sinyal dan keterarahan antena terhadap BTS yang dituju

\subsection{Pengukuran Transfer Rate Data}

Pengujian transfer data dilakukan dalam dua tahap dan dua kondisi yaitu pada siang dan malam hari serta dalam kondisi indoor dan outdoor menggunakan perangkat lunak QXDM (Qualcomm extensible) Diagnostic Monitor), Speedtest dan IDM (Internet Download Manager).

1. Pengujian di tempat indoor pada waktu siang hari dan tanpa menggunakan antena dengan reflektor wajanbolik

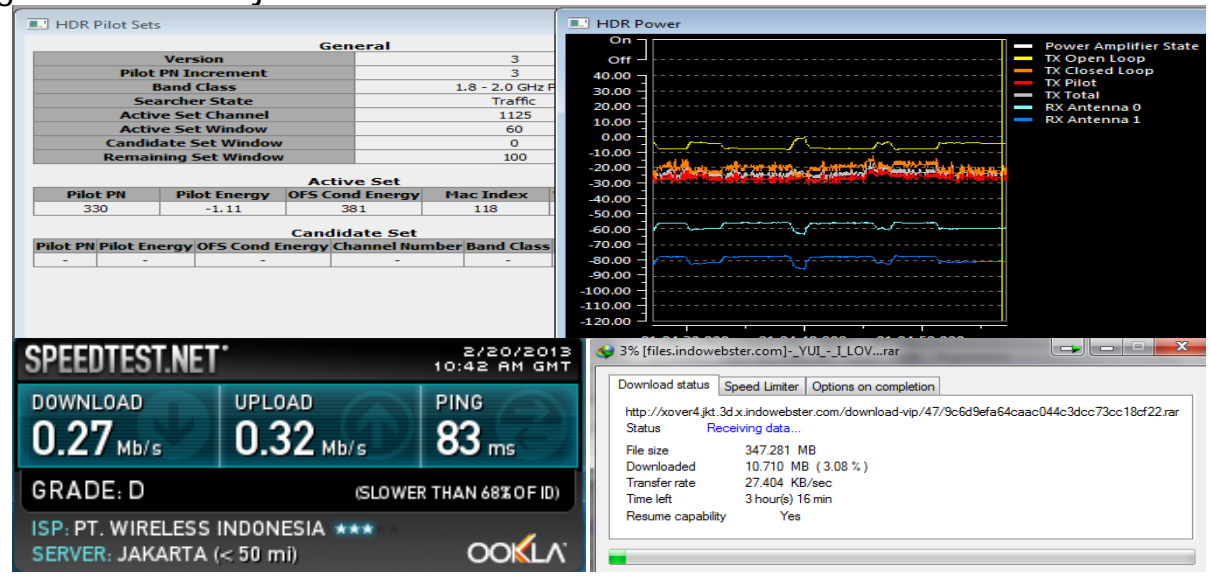

\section{Gambar 10. Pengujian indoor, siang hari, tanpa antena}

Pada pengujian indoor, siang hari, tanpa antena didapat rata-rata level sinyal sebesar -79 $\mathrm{dBm}$, dengan throughput sebesar 0,27 Mbps dan transfer rate sebesar 27,404 KBps. 
2. Pengujian di tempat indoor pada waktu siang hari menggunakan antena dengan reflektor wajanbolik

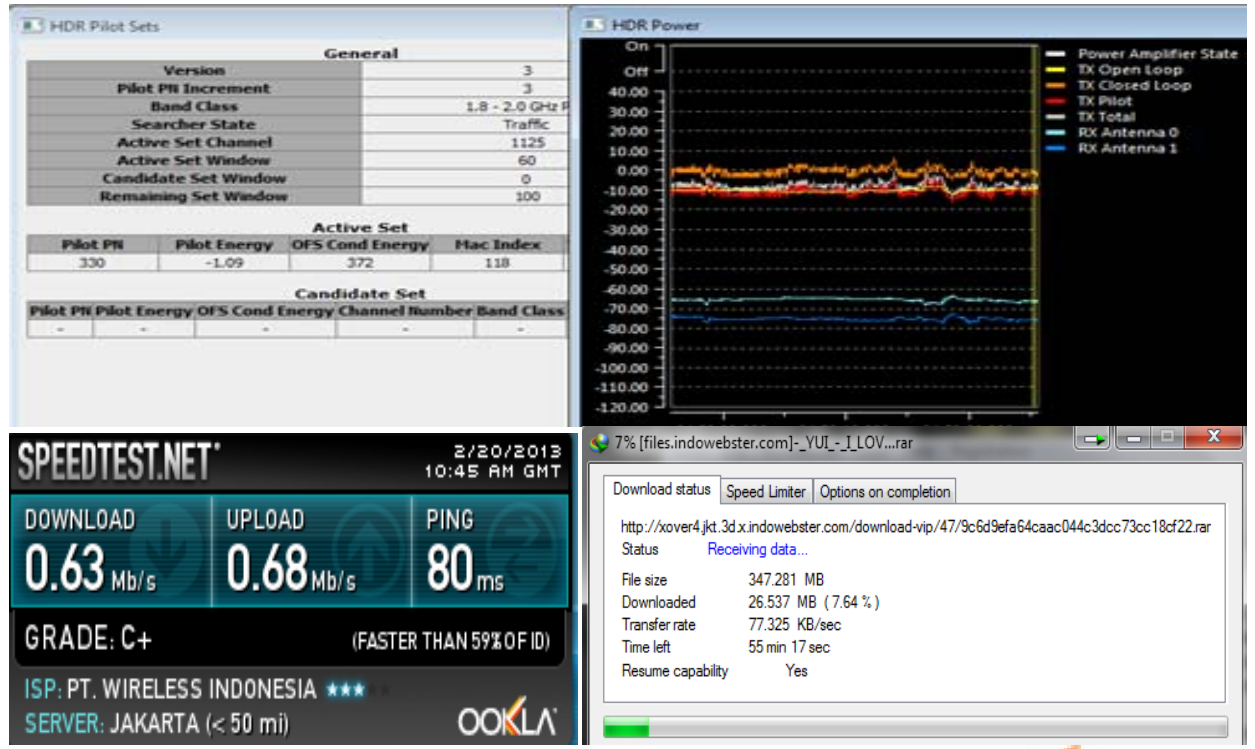

Gambar 11. Pengujian indoor, siang hari, dengan antena

Pada pengujian indoor, siang hari, dengan antena didapat rata-rata level sinyal sebesar -75 $\mathrm{dBm}$, dengan throughput sebesar 0,63 Mbps dan transfer rate sebesar 77,325 KBps.

3. Pengujian di tempat indoor pada waktu malam hari tanpa menggunakan antena dengan reflektor wajanbolik

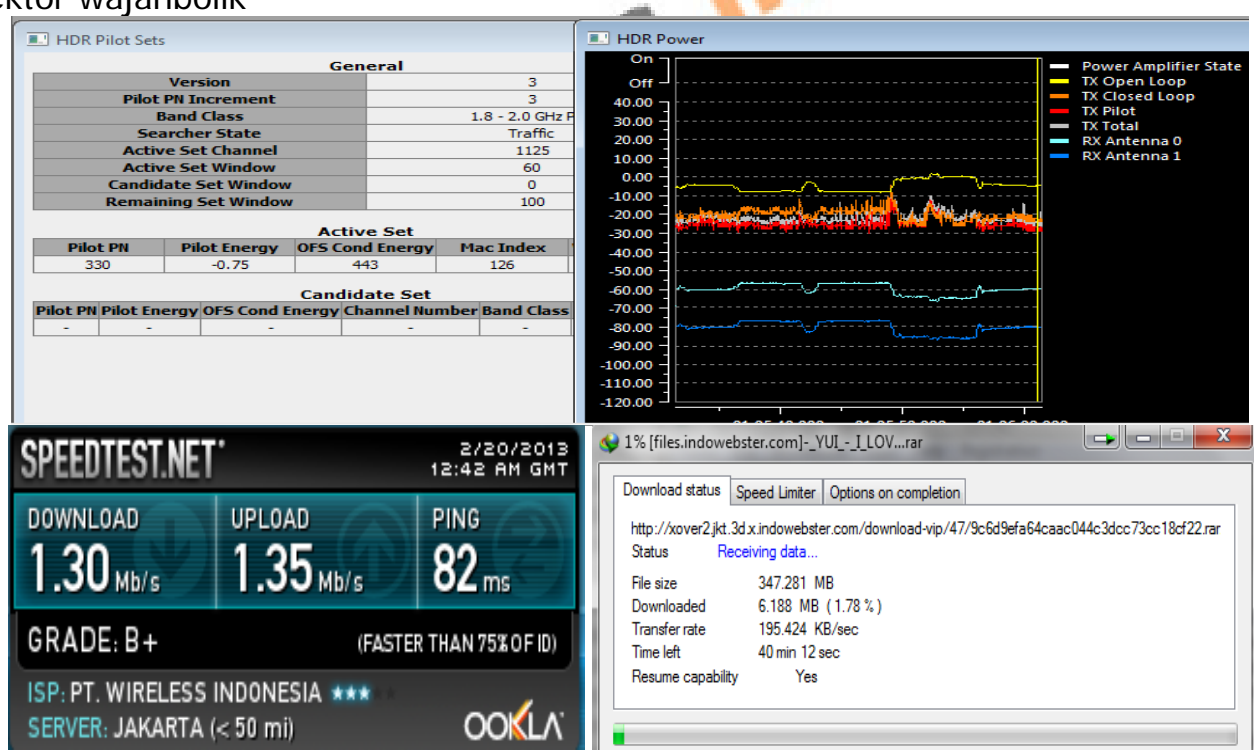

Gambar 12. Pengujian indoor, malam hari, tanpa antena

Pada pengujian indoor, malam hari, tanpa antena didapat rata-rata level sinyal sebesar -80 $\mathrm{dBm}$, dengan throughput sebesar 1,30 Mbps dan transfer rate sebesar 195,424 KBps. 
4. Pengujian di tempat indoor pada waktu malam hari menggunakan antena dengan reflektor wajanbolik

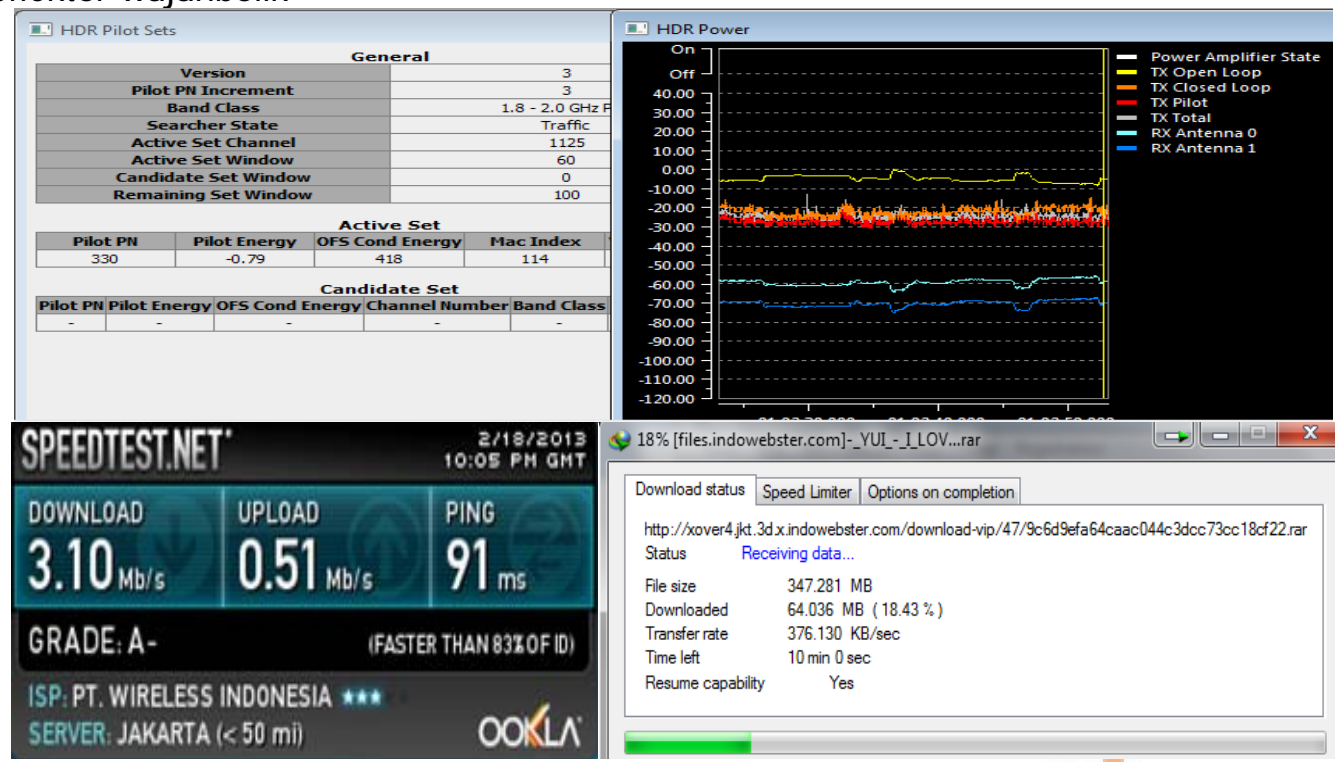

\section{Gambar 13. Pengujian indoor, malam hari, dengan antena}

Pada pengujian indoor, malam hari, dengan antena didapat rata-rata level sinyal sebesar -70 $\mathrm{dBm}$, dengan throughput sebesar 3,10 Mbps dan transfer rate sebesar 376,130 KBps.

5. Pengujian di tempat outdoor pada waktu siang hari tanpa menggunakan antena dengan reflektor wajanbolik

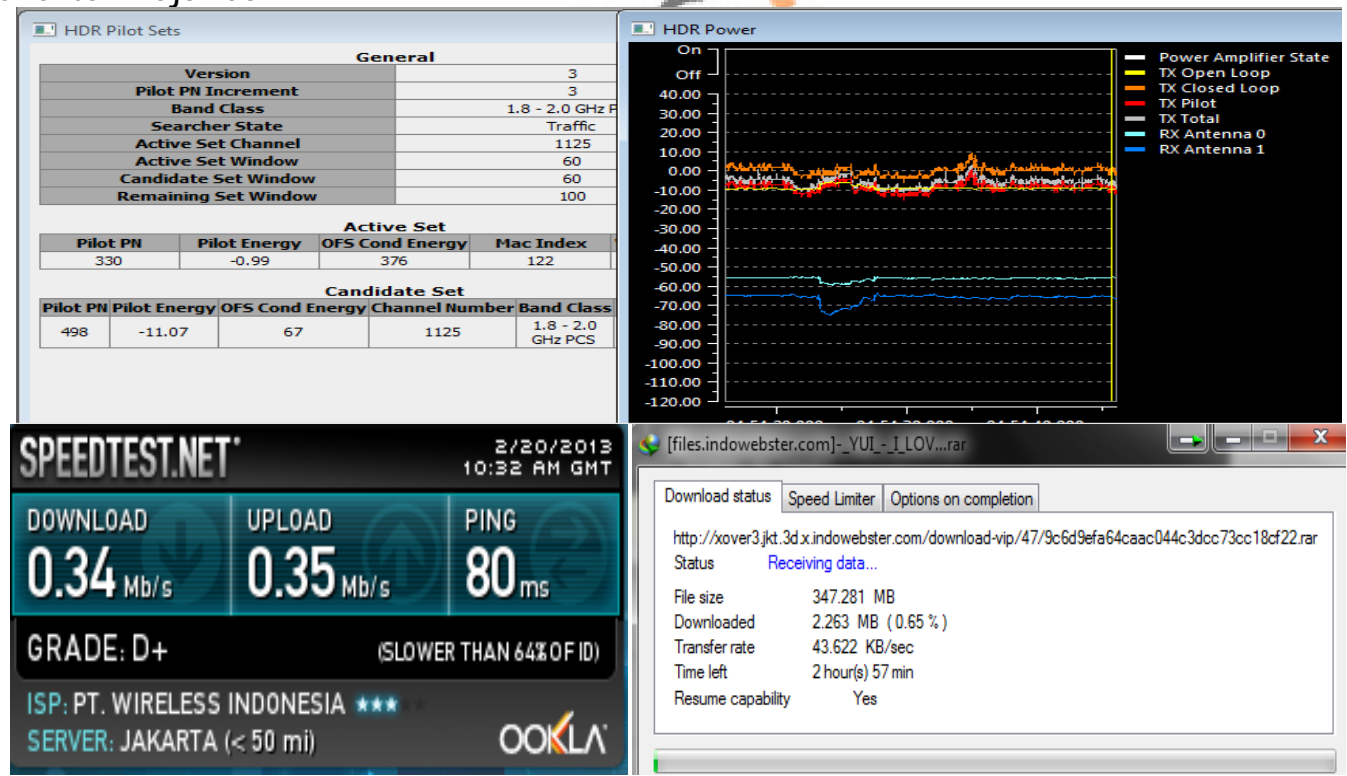

Gambar 14. Pengujian outdoor, siang hari, tanpa antena

Pada pengujian outdoor, siang hari, tanpa antena didapat rata-rata level sinyal sebesar - 66 $\mathrm{dBm}$, dengan throughput sebesar 0,34 Mbps dan transfer rate sebesar 43,622 KBps. 
6. Pengujian di tempat outdoor pada waktu siang hari menggunakan antena dengan reflektor wajanbolik
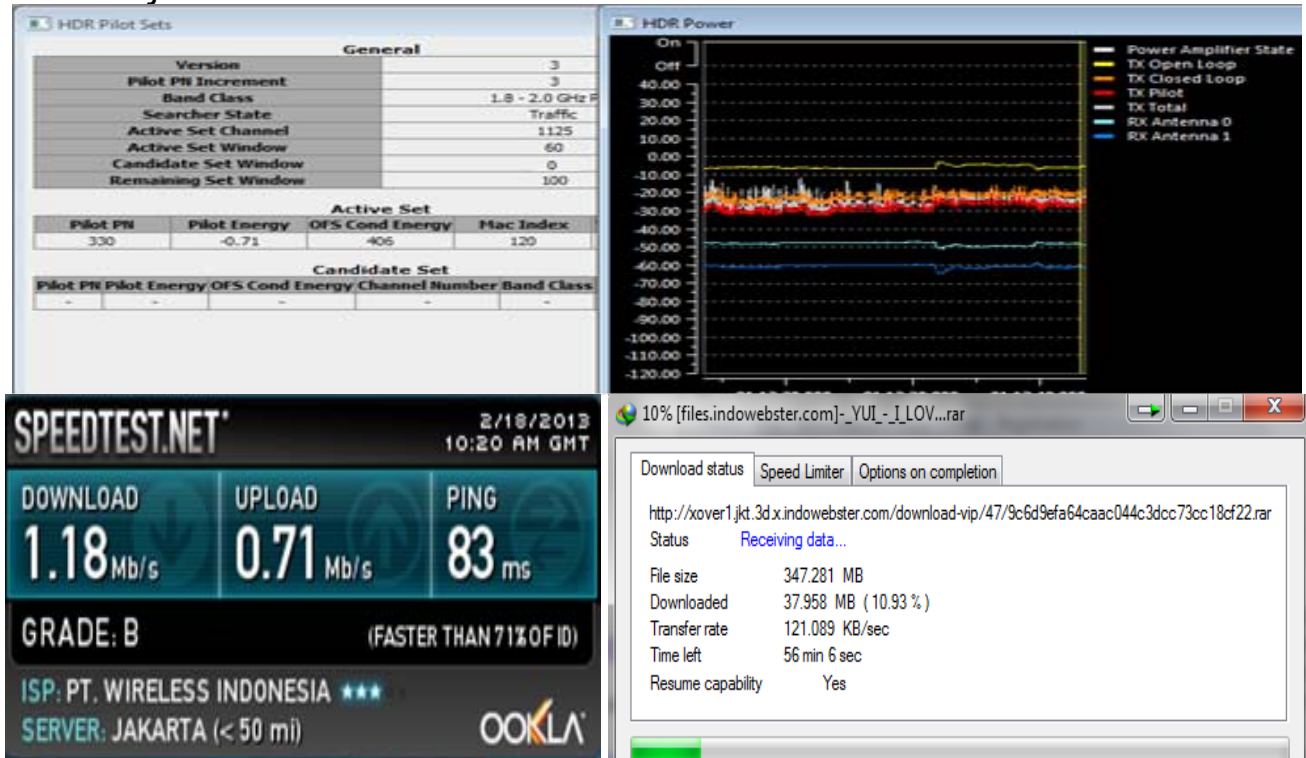

\section{Gambar 15. Pengujian outdoor, siang hari, dengan antena}

Pada pengujian outdoor, siang hari, dengan antena didapat rata-rata level sinyal sebesar -60 $\mathrm{dBm}$, dengan throughput sebesar 1,18 Mbps dan transfer rate sebesar 121,089 KBps.

7. Pengujian di tempat outdoor pada waktu malam hari tanpa menggunakan antena dengan reflektor wajanbolik
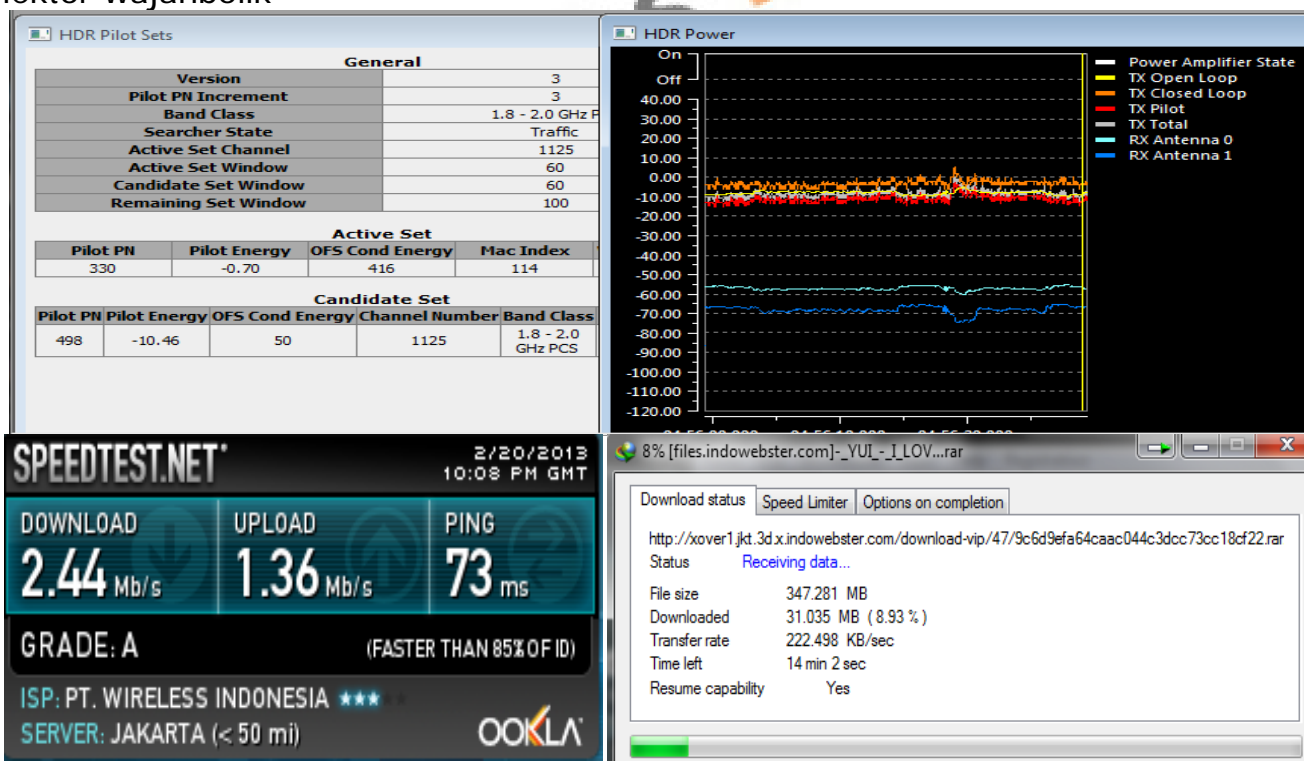

Gambar 16. Pengujian outdoor, malam hari, tanpa antena

Pada pengujian outdoor, malam hari, tanpa antena didapat rata-rata level sinyal sebesar - 69 $\mathrm{dBm}$, dengan throughput sebesar 2,44 Mbps dan transfer rate sebesar 222,498 KBps. 
8. Pengujian di tempat outdoor pada waktu malam hari menggunakan antena dengan reflektor wajanbolik
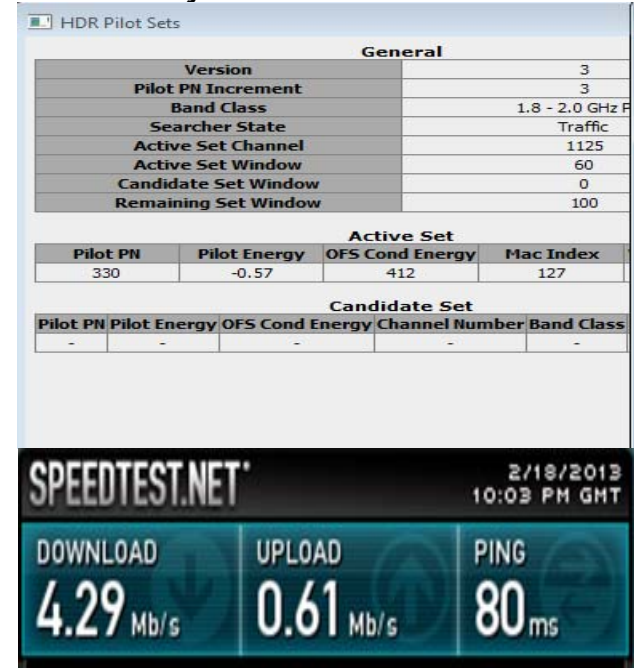

GRADE: A

(FASTER THAN 87\% OF 10)

ISP: PT. WIRELESS INDONESIA ***

SERVER: JAKARTA $(<50 \mathrm{mi})$

\section{OOKLN}
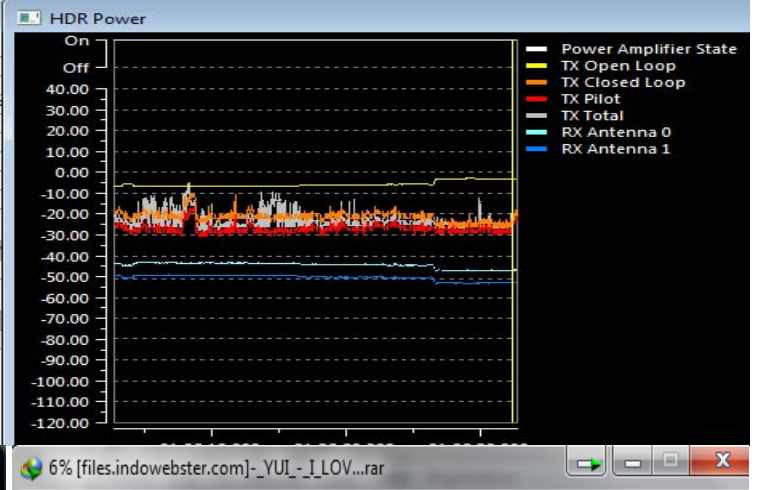

\begin{tabular}{|l|l|l|}
\hline Download status & Speed Limiter & Options on completion \\
\hline
\end{tabular}

http://xover4.jkt.3d x.jindowebster.com/download-vip/47/9c6d9efa64caac044c3dcc73cc18cf22.rar

Status Receiving data...

File size $\quad 347.281 \mathrm{MB}$

Downloaded 21.164 MB $(6.09 \%)$

Transfer rate $\quad 555.280 \mathrm{~KB} / \mathrm{sec}$

Time left $\quad 11 \mathrm{~min} 56 \mathrm{sec}$

Resume capability Yes

Gambar 17. Pengujian outdoor, malam hari, dengan antena

Pada pengujian indoor, siang hari, tanpa antena didapat rata-rata level sinyal sebesar - 50 $\mathrm{dBm}$, dengan throughput sebesar 4,29 Mbps dan transfer rate sebesar 555,280 KBps.

Tabel 3. Hasil uji transferdata

\begin{tabular}{|c|c|c|c|c|c|c|c|}
\hline \multirow[b]{3}{*}{ Waktu } & & \multicolumn{6}{|c|}{ Uji Transfer Data } \\
\hline & & \multicolumn{3}{|c|}{ Indoor } & \multicolumn{3}{|c|}{ Outdoor } \\
\hline & & $\begin{array}{l}\text { Sinyal } \\
\text { pada } \\
\text { QXDM } \\
\text { (dBm) }\end{array}$ & $\begin{array}{c}\text { Through } \\
\text { put } \\
\text { (Mbps) }\end{array}$ & $\begin{array}{c}\text { Transfer } \\
\text { Rate } \\
\text { rata-rata } \\
\text { Pada } \\
\text { I DM } \\
\text { (KBps) }\end{array}$ & $\begin{array}{c}\text { Sinyal } \\
\text { pada } \\
\text { QXDM } \\
\text { (dBm) }\end{array}$ & $\begin{array}{c}\text { Through } \\
\text { put } \\
\text { (Mbps) }\end{array}$ & $\begin{array}{c}\text { Transfer } \\
\text { Rate } \\
\text { rata-rata } \\
\text { Pada } \\
\text { IDM } \\
\text { (KBps) }\end{array}$ \\
\hline \multirow[t]{2}{*}{ Siang } & $\begin{array}{l}\text { Tanpa } \\
\text { Antena }\end{array}$ & -79 & 0,27 & 31,092 & -66 & 0,34 & 40,59 \\
\hline & $\begin{array}{l}\text { Dengan } \\
\text { Antena }\end{array}$ & -75 & 0,63 & 73,473 & -60 & 1,18 & 144,325 \\
\hline \multirow[t]{2}{*}{ Malam } & $\begin{array}{l}\text { Tanpa } \\
\text { Antena }\end{array}$ & -80 & 1,30 & 163,792 & -69 & 2,44 & 289,608 \\
\hline & $\begin{array}{l}\text { Dengan } \\
\text { Antena }\end{array}$ & -70 & 3,10 & 367,12 & -50 & 4,29 & 559,07 \\
\hline
\end{tabular}

Dari Tabel 3 dapat diketahui bahwa dengan menggunakan antena wajanbolik baik itu pada siang hari ataupun malam hari dan juga pada keadaan indoor ataupun outdoor terlihat adanya peningkatan level sinyal terima yang terbaca pada software QXDM juga terlihat peningkatan throughput dan transfer rate yang terbaca pada IDM dan speedtest.

Peningkatan throughput terendah diperoleh pada pengujian dengan menggunakan antena wajanbolik pada siang hari dan pada keadaaan indoor yaitu sebesar 0,36 Mbps yang hanya menghasilkan kenaikkan rata - rata transfer rate data sekitar 42 KBps sedangkan 
peningkatan throughput terbesar diperoleh pada pengujian dengan menggunakan antena wajanbolik pada malam hari dengan keadaan outdoor yaitu sebesar 1,85 Mbps yang menghasilkan kenaikkan rata - rata transfer rate data sekitar 269 KBps jika dibandingkan dengan pengujian tanpa menggunakan antena pada waktu yang sama.

\subsection{Kesimpulan}

\section{KESI MPULAN DAN SARAN}

Berdasarkan hasil penelitian dan pengujian, maka dapat diambil kesimpulan dari percobaan yang telah dilakukan adalah sebagai berikut:

1. Antena dengan reflektor wajanbolik termasuk antena directional yang mempunyai keterarahan sinyal dilihat dari pola radiasi yang di dapat.

2. Antena dengan reflektor wajanbolik dapat memberikan gain sebesar $15,530 \mathrm{~dB}$ berdasarkan pengukuran dan sebesar 15,156 dB berdasarkan perhitungan dengan perbedaan gain sebesar 0,374 dB.

3. Peningkatan penerimaan sinyal modem dapat dibantu menggunakan antena dengan reflektor wajanbolik yang mendapatkan kenaikan sinyal terendah pada pengujian dalam keadaan indoor di siang hari yaitu sebesar $4 \mathrm{~dB}$ dan mendapatkan kenaikan sinyal tertinggi pada pengujian dalam keadaan outdoor di malam hari yaitu sebesar $19 \mathrm{~dB}$ dibandingkan pengujian tanpa menggunakan antena.

4. Peningkatan throughput diiringi juga oleh peningkatan transfer data. Transfer data rata - rata dapat meningkat antara 42 KBps sampai 269 KBps dari transfer data awal yang tanpa menggunakan antena dengan reflektor wajanbolik.

\subsection{Saran}

Adapun saran - saran yang dapat diberikan untuk penelitian ini di masa depan agar lebih baik, yaitu :

1. Pemilihan bahan dan material pembuat reflektor yang lebih tepat serta penggunaan peralatan yang lebih diperhatikan kepresisiannya agar hasil yang diperoleh sesuai dengan perhitungan

2. Penggunaan software USB adapter dengan versi yang terbaru sehingga mudah dalam pembacaan nilai jevel sinyal yang diperoleh.

3. Diperlukan mounting atau tiang yang cukup kuat dan tinggi karena alat ini juga berpengaruh terhadap angin dalam koneksinya dan juga pada saat pointing antena wajanbolik harus tepat mengarah ke BTS yang dituju dan di usahakan harus dalam keadaan clear LOS ( Line of Sight).

\section{DAFTAR RUJ UKAN}

Stallings,W. (2007). Komunikasi dan Jaringan Nirkabel. Jakarta: Erlangga.

Purbo, O. W. (2007). Panduan Praktis RT/RW-net \& Antena Wajanbolik. Jakarta: P.T. Prima Infosarana Media.

Trisapto, P. (2004). Diktat Kuliah Perencanaan Sistem Radio. Bandung : Teknik Elektro Institut Teknologi Nasional.

Rahman, W. P. (2011). Perancangan dan Realisasi Penguat Pada Wifi. Bandung: Teknik Elektro Institut Teknologi Nasional.

Yurandi, N. (2012). Perancangan dan Implementasi Reflector Antena Wifi dengan Frekuensi 2,4 GHz. Bandung: Teknik Elektro Institut Teknologi Nasional. 